\title{
CONTROLE DE ESTERILIZAÇĀO. O PAPEL DA ENFERMEIRA.
}

\section{Maria Helena Sant 'ana Mandelbaum *}

MANDELBAUM, M.H.S. Controle de esterilização. O papel da enfermeira. Rev. Esc. Enf. USP,

São Paulo, 14 (3): 237-242, 1980.

Neste artigo sto abordados os principais métodos, disponiveis até o momento em noseo meio, para o controle dos processos de esterlizaçōo, salientando-se a importância da utilizaç̄o de tais metodos como parte integrante dos processos de prevencão e combate ds infecçóes hospttalares

\section{INTRODUÇÃO}

Apesar da evolução tecnológica no campo da aparelhagem destinada à esterilizaçáo, o controle dos processos em suas diversas fases é uma preocupação do pessoal hospitalar. Tais controles revestem-se de enorme importância, quando consideramos que estáo inseridos dentro de uma preocupaçáo mais ampla que é o controle da infecção. Neste aspecto a enfermagem desempenha papel relevante no que se refere d identificaçăo e correção das falhas, através da implementação de medidas seguras para o controle dos processos de esterilização empregados pela instituição.

ZANON5 refere que existem três vias principais de transmissáo dentro do processo de infecção:

1. transmissáo por contato;

2. transmissto mediante veículo e

3. transmissto através do ar.

No presente trabalho temos particular interesse pela transmissáo por contato que, segundo o referido autor, pode se processar de duas formas principais: ou doentes;

a) contágio direto entre o hospedeiro susceptivel e portadores assintomáticos

b) contágio indireto: contato entre pessoas susceptíveis e objetos inanimados, com transferência de material através das vias de acesso (pele, boca, mucosas, etc.).

No contágio indireto, o instrumental médico-cirúrgico, assim como toda a variedade de material esterilizado, representa um elemento potencialmente responsável pela veiculação de bactérias, o que reforça a importância do controle dos processos de esterilização a que são submetidos, bem como da manutenção das condiç̄̄es de esterilidade até o momento da utilização desse material. Segundo TIBIRIÇ $\AA^{4}$, as infecçóes podem decorrer de vários fatores, dentre os quais:

- falhas nas técnicas de esterilização do instrumental cirúrgico, roupas;

\footnotetext{
- Auxiliar de Ensino da disciplina Enfermagem em Centro Cirúrgico da EEUSP.
} 
- mau funcionamento dos aparelhos de esterilização;

- manipulação incorreta do material estéril, por falta de orientação quanto aos princípios de assepsia;

- utilização incorreta dos métodos de antissepsia por parte da equipe cirúrgica; cirúrgicas;

- desconhecimento ou displicência na utilização das técnicas de paramentação

- problemas relacionados à planta do Centro Cirurgico (dependências fora dos padrôs recomendados; desrespeito aos limites e barreiras assépticas).

PERKINS 3 refere que as falhas na técnica de esterlização resultam de fatores relacionados principalmente a:

- desconhecimento das características de funcionamento dos aparelhos utilizados para esterilizaçăo;

- métodos incorretos de preparo e acondicionamento do material, sem observação dos requisitos básicos preconizados;

- excesso de carga dos aparelhos, na tentativa de se obter maior produção, resultando em impossibilidade de remoçáo do ar e, conseqüentemente, em impossibilidade de penetração do vapor;

- falhas quanto ao período de exposição ao agente esterilizante;

- inadequação do método de esterilização ao material (ex.: esterilização em autoclave de materiais impermeáveis ao vapor, como óleos);

- estabelecimento de métodos de esterilização em que o reagente sofre alteraçð̄es mesmo exposto a temperaturas e pressð̋es insuficientes para que a esterilização se processe;

- falha nos equipamentos devido à falta de manutenção e mesmo falha no manejo por parte do pessoal.

GASPERINI 1 refere que as falhas acima citadas são agravadas por desconhecimento do pessoal acerca dos princípios relacionados aos processos utilizados, e acrescenta ainda:

- mistura de materiais de superfície e densidade;

- empacotamento incorreto do material.

\section{CONTROLES DE ESTERILIZAÇĀO}

Com o objetivo de reduzir o risco de falha durante os processos de esterilização, vários meios auxiliares têm sido criados. Alguns destes meios já vêm acoplados aos aparelhos, outros sáo de utilizaçáo sistemática, existindo ainda os controles periódicos. GASPERINI ${ }^{1}$ classifica os controles em:

1 - Controles Mecânicos: geralmente acoplados aos aparelhos. Dentre estes os mais importantes são; Control);

a) Gráfico de Indicação de Tempo e Temperatura (Temperature Recorder

b) Manômetro (Jacket): indica a presş̃o da câmara externa ou linha de vapor; 
c) Manovacuômetro (CHAMBER): indica a pressão ou vácuo na câmara interna;

d) Lâmpadas Piloto: lâmpadas que indicam por um sinal luminoso a fase do ciclo em que se encontra o aparelho;

e) Pressostato, Termostato e Válvulas de Segurança: para assegurar a manutenção da temperatura e pressão a niveis corretos.

Tais componentes precisam ser periodicamente revisados por técnicos especializados e, quando se verifica qualquer falha, deve-se suspender a utilização do aparelho até que seja revisto e testado.

2 - Controles Químicos: baseiam-se na reação de um determinado composto químico quando sob a ação de uma dada pressão, temperatura, ou de um agente químico. Comumente estes controles são encontrados sob a forma de tiras ou ampolas nas quais se funde ou inocula uma dada substância química, que será o indicador. Abaixo sáo citados os controles químicos mais utilizados:

a) Fitas indicadoras (Strip): são tiras de papel impregnadas com uma solução reagente, colocadas em cada pacote ou caixa de instrumental. Deve-se ter o cuidado de se manter uma das extremidades dentro e a outra fora. Este indicador apresenta o inconveniente de só permitir a deteç̧ão da falha após a abertura do pacote. É um indicador relativamente barato mas bastante limitado quanto à sua eficácia.

b) Indicadores autoadesivos: sâo tiras adesivas utilizadas para o fechamento dos pacotes, e que contém listras reativas impressas, que se tornam escuras ao contato com o vapor e temperatura. Este tipo de fita é utilizada ainda para teste matinal do aparelho, quando se realiza o primeiro ciclo do dia e se deseja verificar se a entrada de vapor está se processando satisfatoriamente. Uma das críticas feitas a este tipo de teste é sua aderência aos campos e com isso sua inutilização. Uma das formas de evitar este problema é orientar o pessoal de enfermagem a retirar as fitas antes de enviar os campos para a lavanderia.

c) Selos de esterilização: para colocação externa em pacotes, frascos, etc.

d) Ampolas com reagentes: são compostos químicos líquidos, que mudam de cor sob ação do calor. São caros e também não são precisos.

e) Embalagens com indicador: sáo embalagens de papel, plástico ou poliamida que já vêm impregnadas com o reagente.

Como foi referido, tais testes devem ser utilizados unicamente como meios auxiliares, visto que são baseados no contato de um determinado agente com uma substância química. Tais métodos năo garantem que o material esteja esterilizado; indicam, apenas, que o material foi submetido a um processo de esterilização. Isto é extremamente importante, pois, como sabemos, a esterilização depende não só do contato, mas de que este contato se dê a temperaturas, pressoes e tempos de exposição adequados.

Deve-se lembrar também que a utilização destes métodos está sujeita, ainda, à interferência de inúmeros fatores, dentre os quais: quedas de nivel da rede de vapor, colocação incorreta do material nos aparelhos, variaçôes de temperatura nas diversas partes do aparelho. Assim, para que se pudesse ter maior grau de confiança nestes reagentes seria necessário utilizar simultâneamente reagentes externos e internos, 0 que tornaria altamente oneroso e impraticável o processo. 
Vê-se, pois, que tais testes limitam-se a diferenciar o material submetido a determinado processo de esterilização, sem que todavia se possa garantir que o material esteja estéril.

Estas falhas são de caráter quantitativo, como já foi referido, e entre elas podemos citar: ausência de vapor no interior da câmara, temperatura insuficiente, obstruç̃o à entrada de vapor, etc. A utilidade precípua de tais métodos é detectar possíveis falhas com a aparelhagem, principalmente quando o controle é feito em todos os pacotes e são obedecidas rigorosamente as especificaçớes do fabricante.

Como a utilização de métodos biológicos não pode ser feita intensivamente pelas instituições, torna-se necessário um recurso auxiliar, para ser usado com maior freqüência e com resultados mais rápidos. Neste aspecto, os métodos acima referidos mostram-se importantes visto que, como dissemos, muitos já estão acoplados ao aparelho, querendo apenas que um funcionário orientado acompanhe o ciclo e verifique se os dados registrados estão de acordo com os valores pré-estabelecidos.

\section{TESTES BIOLOGICOS}

Como se pode observar pelo exposto, nenhum dos métodos de esterilização acima referidos apresenta resultados seguros e conclusivos. Todos eles revelam a passagem pelo processo, mas não garantem a sua eficácia.

PERKINS 3 refere que os melhores métodos para a confirmação de que o processo de esterilização se processou adequadamente são os de natureza biológica.

Quando conduzidos adequadamente os testes biologicos são os mais efetivos para o estabelecimento de padróes de conduta relacionados aos processos de esterilização. Isto porque para que tais métodos sejam confiáveis, deve-se estabelecer uma rotina para a sua execução, obedecendo-se rigorosamente a todas as determinaçóes, desde a colocaç̃̃o dos cadarços ou tiras nos pacotes até inoculação no laboratório ${ }^{2}$.

Alguns aspectos importantes devem ser ressaltados, para se garantir a utilização correta dos testes biológicos.

1 - Seleção de Bacilos. Devem ser selecionados bacilos que comprovadamente apresentem alta resistência aos métodos de esterilização. Contrariamente ao que se acredita comumente, o esporo do Bacilo Subtilis não é o mais resistente ao calor; submetido a $104^{\circ} \mathrm{C}$ por 15 minutos, sob a ação do calor úmido, pode ser destruído; só deve ser utilizado com calor seco (estufa) e esterilização pelo óxido de etileno. 0 Bacilo sterotermóphilus é um dos microorganismos mais resistentes ao calor, resistindo até 12 minutos a $121^{\circ} \mathrm{C}$ sob vapor. E o microorganismo escolhido para os esterilizadores a vapor (autoclave).

2 - Utilização dos testes biológicos. Os bacilos para os testes podem ser obtidos tanto sob a forma de cadarços contaminados como de tiras impregnadas com populaçóes conhecidas dos referidos bacilos, fornecidas por firmas especializadas. eficácia.

Deve-se tomar alguns cuidados na realização dos testes, para se assegurar sua

a) Deve-se selecionar 1 ou 2 pacotes, dentre os de maior dimensáo usualmente utilizados na instituição (LAP, acessório de Bird, caixa cirúrgica, etc.).

b) Deve-se preparar o pacote da forma rotineira, colocando-se a tira ou cadarço 
com bacilo no ponto de maior dificuldade de acesso do agente esterilizante (geralmente no meio); identifica-se o pacote teste.

c) A seguir distribui-se a carga no aparelho a ser testado, tendo-se o cuidado de colocar os pacotes de testes nos pontos de maior dificuldade de penetração do vapor.

d) Processa-se a esterilização de forma usual.

e) Ao término do ciclo enviam-se os pacotes testes ao laboratório, para que sejam retirados os cadarços e se processe a inoculação no meio de cultura. Deve-se evitar a manipulação dos cadarços e fitas, deixando-se a cargo do laboratório a sua retirada do pacote.

f) Os testes devem ser cadastrados, tomando-se os seguintes dados: data do teste, aparelho testado, tipo de carga, número de tiras, localização das tiras, tempo, temperatura, periodo de exposiçáo e quem realizou o teste.

g) Deve-se aguardar o resultado dos testes. A liberação do aparelho só pode ser feita após tais resultados. Isto implica em que os testes nos aparelhos nao devem ser realizados de uma só vez, pois, além de sobrecarregar o laboratório, obrigaria a paralizaçðo do funcionamento do Centro de Material. Deve-se estabelecer um calendário para cada aparelho, para evitar tais inconvenientes.

3 - Freqüência dos testes. Os testes biológicos por serem onerosos não podem ser realizados diariamente. A freqüência preconizada como ideal é a de que cada aparelho seja quinzenalmente testado. Devem-se testar todos os aparelhos em uso (estufa, autoclaves a vapor e a gás). Entretanto, toda vez que qualquer aparelho seja submetido a revisão ou conserto, deve-se obter o resultado dos testes biológicos antes de se colocar o aparelho em uso.

\section{CONCLUSÃO}

O estabelecimento e implementação de padrōes para o controle dos processos utilizados na esterilização de material devem ser preocupação da enfermeira em qualquer instituição onde se processe a esterilização de material.

A utilização de testes seguros é uma das condições imprescindiveis para assegurar o formecimento e utilização de material dentro de padróes adequados de esterilização e conseqüentemente reduzir a cadeia de fatores responsáveis pelos altos indices de infecção observados no momento.

MANDELBAUM, M.H.S. Sterilization control. Role of the nurse. Rev. Esc. Enf. USP, São Paulo, $14(3): 237-242,1980$.

The author describes methods and techniques of sterilization control and emphatizes its importance in the control of infection.

\section{REFERENCIAS BIBLIOGRAFICAS}

1. GASPERINI, R.J. Controle de esterilização. Rev. paul. Hosp., São Paulo, 25 (3): 123-6, mar. 1977.

2. LITSKY, B.Y. Sterility assurance in hospital. Who's responsible. AORN J., Denver, 27 (2): 200-1, feb. 1978. 
3. PERKINS, J.J. Principles and methods of sterilization in health sciences. 2. ed., Illinois, Charles C. Thomas, 1969. p. 483-500.

4. TIBIRIÇÁ, C.C. Atuaçâto do pessoal de enfermagem nas medidas de controle de infecção hospitalar. Rev, Bres. Enf., Rio de Janeiro, $27(4): 462-71$, out./dez. 1974.

5. ZANON, U. Fundamentos para o controle das infecções adquiridas em hospital. Semestre Terapêutico, 28: 2-12, dez. 1973. 